\title{
A VOZ DOS PROFESSORES BAIANOS NO INÍCIO DA REPÚBLICA: A REVISTA DO ENSINO PRIMARIO (1892-1893)
}

\author{
Elizabete Conceição Santana \\ UNEB \\ ecsantana@atarde.com.br
}

\section{RESUMO:}

Este artigo trata de um periódico criado por professores de escolas públicas primárias do Estado da Bahia, Brasil, em 1892, três anos depois da República no país. Na revista os professores falam acerca de suas condições de trabalho, da realidade das escolas, das normas legais impostas pelas autoridades governamentais e das políticas públicas para a educação. Além de representar um diagnóstico da educação, os textos refletem a tensão entre políticas públicas para a construção de um sistema de educação no Estado e as dificuldades para expandir a escola elementar na primeira República.

Palavras-chave: Professores, História, Memórias

\section{THE VOICE OF BAIANOS TEACHERS IN BEGIN OF REPUBLIC: THE JOURNAL OF PRIMARY EDUCATION (1892-1893)}

\begin{abstract}
:
This text is about a magazine created by public school teachers of primary education in the State of Bahia, Brazil, in 1892, three years after the proclamation of the Republic in the country. In the magazine teachers talk about their working conditions, reality of schools, legal standards imposed by government authorities and public policy for education. Besides representing a diagnosis of the education, the texts reflect the tension between public policy for establishing a system of education in the State and the difficulties of expanding the public elementary school in the First Republic.
\end{abstract}

Keywords: Teachers, History, Memories.

\section{Introdução ${ }^{1}$.}

Deve-se reconhecer que embora as normas legais incluam determinações importantes sobre a organização da escola, as rotinas escolares, materiais didáticos, o sistema de provas e exames, o horário das atividades, o sistema disciplinar, e outros itens, é no cotidiano da escola que tais aspectos assumem sua forma real que muitas vezes destoa dos preceitos da lei. De modo que para estudar os currículos prescritos e suas relações com o currículo em uso nas escolas primárias do Estado da Bahia, no período de 1889-1930, além das leis de reforma e dos seus regulamentos, pretende-se levantar documentos de professores ou de observadores das práticas vigentes no espaço escolar - inspetores, delegados escolares, diretores, alunos, exalunos e jornalistas da época. O objetivo é fazer, o resgate de um aspecto da memória da educação ainda pouco trabalhado entre nós e identificar as distâncias e aproximações existentes entre o currículo prescrito pela administração do ensino e o currículo em uso na sala de aula. 
Na perspectiva de contrapor diferentes discursos e visões sobre a escola, o Projeto "MUDANÇAS CURRICULARES NA CONSTRUÇÃO DA ESCOLA PRIMÁRIA NA BAHIA: Os currículos prescritos nas reformas do ensino e suas relações com o currículo em uso nas escolas (1889-1925)" também está orientado para a recolha de escritos de professores. Em determinado momento, a consulta ao Catálogo do Setor de Periódicos Raros da Biblioteca Pública do Estado da Bahia indicou a existência de uma Revista do Ensino Primário da qual foram localizados 12 números.

A experiência vivenciada na execução do projeto vem demonstrando que, apesar do difícil acesso, é possível chegar aos documentos oficiais utilizando os guias de fontes anteriormente referidos e outros que se encontram disponíveis. Quanto aos documentos que expressam as idéias e as falas dos atores mais diretamente envolvidos na prática e nas relações da escola e da sala de aula, eles precisam ser incessantemente buscados. Não existem guias, só pequenos indícios. De modo que o encontro da Revista do Ensino Primário foi considerado um importante achado. É de se notar que a Revista não se encontra entre os periódicos baianos relacionados no Catálogo on-line de periódicos raros da Biblioteca Nacional.

\section{A Revista do Ensino Primário: "Nos etiam pro causa nóstra pugnamus"}

Os 12 números localizados constituem cadernos numerados sequencialmente cujas capas apresentam sempre o mesmo formato. Na maioria das capas há uma anotação manuscrita indicando que os exemplares da revista recolhidos ao arquivo da Biblioteca Pública do Estado da Bahia foram enviados (ou ofertados?): "Ao Prof. Livino de Amorim Tapera- No Jornal de Notícias" ou endereçados "A illustrada redacção do Jornal de Notícias".

Os números publicados entre $1^{\circ}$ de novembro de 1892 e outubro de 1893 denotam uma regularidade, não havendo informações sobre a extinção da revista que era uma publicação mensal mantida por assinaturas semestral e anual com preços diferenciados para a capital e o interior ${ }^{2}$. 


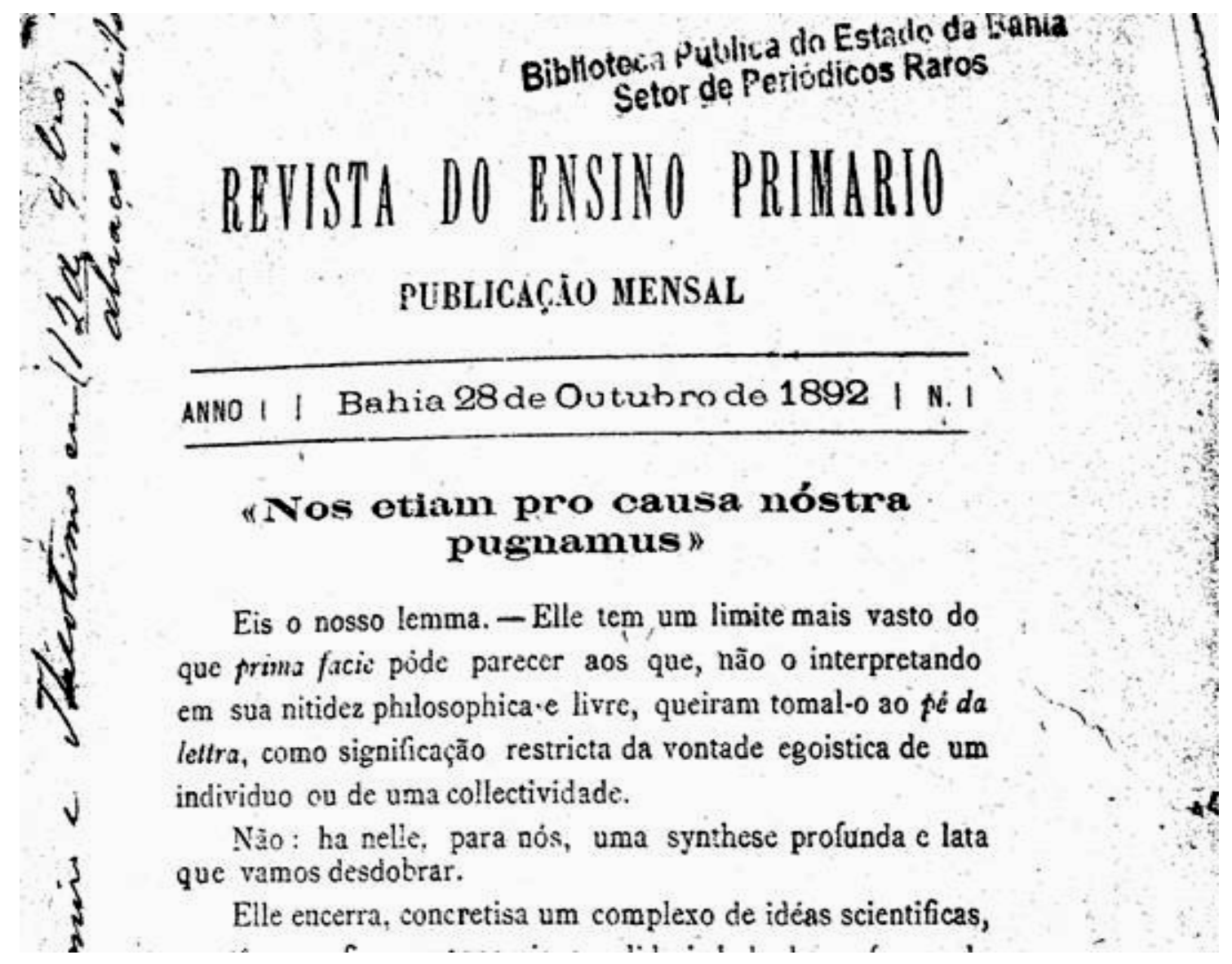

Figura 1. Página 1 do primeiro número da Revista do Ensino Primário.

Fonte: Biblioteca Pública do Estado da Bahia - Setor de Periódicos Raros.

A nota "Pedimos encarecidamente aos que não satisfizeram ainda a assinatura do $1^{\circ}$ semestre, queiram fazel-o, afim de não suspenderem a remessa da Revista", que começa a aparecer no verso da contra capa do número 6, é um indício de possíveis dificuldades no recebimento do valor das assinaturas.

Na capa, o nome dos redatores - Leopoldo dos Reis, Luis Leal e Theotimo de Almeida -, antecedidos do título "professores", indica a vinculação do periódico aos profissionais da educação e às questões do ensino.

No editorial do número 1, datado de 28 de outubro de 1892, os redatores apresentam o lema e os objetivos da Revista, em matéria assinada pelo professor Leopoldo dos Reis (Figura 1).

A Revista estava empenhada na causa do professorado, da criança e do ensino primário. O seu propósito era lutar contra

"as inconguencias de reformas antipedagogicas e anti-cientificas,
desacordo manifesto com a nossa mesologia, legisladas pela craveira
dos caprichos pessoaes e não patrioticos, para transformarem os
professores em uma victima do arbítrio e a criança em um
condemnado a quem foi imposta a sentença brutal de repetir de cor,
apegado a um banco, incompatível com o seu desenvolvimento
physico e com as leis de hygiene applicadas ao caso - umas lições
decoradas, pedantescas, que matam-lheas expansõs do espírito e 
embotam-lhe as faculdades observativas e acquisitivas do aprendizado; (REIS, 1892, p. 2).

Ao declarar o compromisso de lutar junto aos poderes públicos para prover as escolas de material, o redator afirma que "o professorado comprehende que não deve mais viver á redondo de quem quer que seja [...]. É mister que se levante e cure-se radicalmente dessa paralysia moral, dessa indiferença criminosa, em que se afundou para restaurar o uso e o goso pleno de seus direitos" (p.2).

Nas palavras de Luiz Leal (1892, p. 2-3), outro dos três redatores da Revista, o periódico deveria funcionar também como um instrumento de aperfeiçoamento do professorado comprometendo-se a divulgar conhecimentos pedagógicos indispensáveis a um bom professor. Além de cumprir esta promessa através dos artigos e matérias publicadas, os editores divulgam obras consideradas modernas, na seção denominada "Bibliographia". E o verso da capa e da contracapa do periódico foi reservado para a publicação de anúncios de obras destinadas ao professor e de livros didáticos premiados em exposições que eram vendidos nas livrarias Magalhães e Catilina, localizadas em Salvador, capital do Estado.

No verso da capa do número 2, encontra-se o anúncio das obras de Pedagogia de Spencer e Coelho intituladas, respectivamente, de "Educação intellectual, moral e physica, tradução portugueza por Emygdio d'Oliveira" e "Pedagogia moderna, contendo, em resumo, uma descrição do ensino em França". No mesmo local também são anunciadas obras de "Linguistica" e de "Litteratura".

$\mathrm{Na}$ contracapa os anúncios destacam obras didáticas premiadas nas exposições pedagógicas. Entre elas encontram-se livros de leitura e escrita de Hilário Ribeiro, livros de leitura graduada de Zuluar e outros livros.

As duas seções de anúncios estão presentes em todos os números, sempre com as mesmas características.

\section{Contexto de criação da Revista e a tônica dos artigos publicados}

O mote para a construção dos textos pelos redatores e colaboradores é a crítica à legislação vigente, o descaso das autoridades e a incompetência dos administradores e inspetores por desconhecimento do campo educacional e da realidade local. Se isso parece tendencioso, deve-se pensar na situação em que se encontrava o professorado e a educação na Bahia, naquele momento.

Em novembro de 1892, três anos após a proclamação da República, quando a Revista aparece, estava em vigor o Regulamento de 1890 e o Regimento interno das escolas primárias estabelecido em março de1891. Os textos publicados situam-se na transição entre o momento anterior marcado por um Regulamento estabelecido em 1881, portanto, já conhecido dos professores em suas qualidades e problemas, e um novo Regulamento criado para substituir o amplo leque de atos do efêmero Governo de Manoel Vitorino, primeiro governador da Bahia na República. Novas normas administrativas regulavam a vida dos professores e novas determinações sobre o ensino deveriam ser implementadas no ensino primário e secundário.

O novo Regulamento não se diferenciava muito da lei de 1881 e, também, não representava a proposta inovadora esperada para transformar a educação de acordo com as idéias da República. Apesar das dificuldades de efetivar as normas de 1890 e 1891, já estava 
em tramitação um outro projeto de Reforma que incluía medidas consideradas desfavoráveis à classe do professorado, o que parece uma boa motivação para a criação do periódico.

Perpassa por todos os números a preocupação com a reforma vigente e com o projeto em discussão. Já no primeiro número declara-se a competência dos professores para influir nas decisões sobre o ensino, quando Vallasques (1892, p. 14) afirma:

Não é justo, pois, com a pratica que temos de magistério primário e conhecimento de alguns pontos deste Estado advertir aquelles que pretendem decretar uma medida, evitando os effeitos de tentativas mal estudadas? Pois o professorado deve emmudecer diante de assunto tão sério como é o que tratamos, sem procurar escarece-los com as luzes de sua experiência e pratica do ensino?

O papel ativo da Revista e dos professores do Estado da Bahia na discussão das Reformas é ressaltado por Assis (1923 p. 308) que diz:

Hoje, passam as reformas da instrução pública, com o completo silêncio do professorado [...]. Não assim eram passados annos, mesmo na Republica, bastando para exemplo a existência da Revista do Ensino Primário, principalmente em 1893, discutindo, analysando, criticando, na acepção da palavra, todas as resoluções tomadas naquella época[...]. São desses tempos e dessas luctas: Diogo Vallasques, Theotimo d'Almeida, [...], Argemiro Cavalcanti [..]. (Grifo do autor).

Em 1880 o professorado também fez uso de um periódico para divulgar suas idéias em relação à reforma que se anunciava e que se efetivou, em 1881, através da Lei Bulcão. Criaram a Revista científica, literária e noticiosa, A ESCOLA, pertencente ao Grêmio Normalístico que tinha como um dos seus redatores Leopoldo dos Reis, também redator, 13 anos mais tarde, da Revista da Escola Primária. Do periódico foi encontrado apenas o número 1, cujo editorial datado de 7 de setembro diz: "Nesse caminho escabroso a despeito de tantos obstáculos temerosos animamo-nos a apresentar ao público a nossa legenda: Nós etiam pro causa nostra pugnamus”, o mesma lema da Revista do Ensino Primário.

Os diversos artigos assinados por professores questionam itens da legislação, elogiam outros e, principalmente, estão sempre confrontando as imposições da lei com a realidade do ensino no Estado da Bahia. Em alguns casos, certamente devido à predominância entre os autores de professores que militavam na capital, os exemplos tomados para ilustrar as discussões retratam aspectos relativos à realidade local, embora questões gerais sejam também colocadas em discussão como é o caso da obrigatoriedade, dos livros didáticos, da inspeção, do horário ou sessões escolares, das casas de escola, do fundo escolar etc.

A tônica dos artigos são as tensões e conflitos que se estabelecem em relação às mudanças que se tenta instalar. Existe um empenho em demonstrar que a ineficiência atribuída ao professores encobre uma situação de penúria das escolas que atinge, até mesmo, as escolas primárias anexas ao Instituto Normal consideradas na lei como modelo para as demais. Há também um esforço por apontar soluções adequadas à realidade local, mesmo quando se faz uso de argumentos construídos a partir da referência a medidas educacionais postas em prática em outros países. 
No número 2, publicado em dezembro de 1892 uma nota da redação acusa o bom acolhimento da imprensa da capital e de outros pontos do Estado e ressalta a aceitação de assinaturas por parte dos professores públicos e particulares. O número de páginas aumentara para 20, sem incluir capa e contracapa, o que representa mais quatro páginas em relação ao primeiro número.

Os relatos sobre a situação das escolas revelam um conhecimento próprio de "quem faz". Nas páginas do periódico encontram-se propostas de soluções para os problemas da educação como é o caso da obrigatoriedade tratada logo no primeiro número.

Ademais das observações sobre o aspecto físico dos prédios escolares e de outras questões relativas ao ensino, a revista é fonte de informações sobre a prática pedagógica desenvolvida pelos professores, a clientela que estava na escola pública naquele momento e os conhecimentos e saberes profissionais em uso pelos professores. Através dos autores citados, das obras mencionadas e dos argumentos e teses propostas para organizar o ensino e ensinar determinadas disciplinas, é possível encontrar indícios e levantar hipóteses sobre as fontes de que faziam uso os professores para construir o seu conhecimento pedagógico.

\section{A discussão sobre obrigatoriedade escolar}

No número 1, Diogo Vallasques (1892) começa o seu artigo sobre obrigatoriedade escolar perguntando: Deve estabelecer-se já por uma lei a obrigatoriedade do ensino n'este Estado? Posicionando-se sobre a questão, fala do seu próprio desejo: "Ora, eu desejava ver em sua plenitude decretada a obrigatoriedade de ensino primário, e adotada tão salutar medida em todos os recantos d'este vasto Estado; porém sou forçado a modificar o meu desejo pela contigencia do meio, que é tudo para a solução deste problema, a não ser que decretemos uma lei para figurar eternamente no papel." (p.13).

O professor demonstra um real conhecimento da situação da educação, da carga financeira que representaria a ampliação do número de escolas e das limitações dos recursos do Estado para gastos com educação. Conclamando moderação e perseverança, enumera os passos preparatórios para mais tarde tornar efetiva a obrigatoriedade:

Incitemos aos nossos concidadãos para mandarem seus filhos ás escolas; abram-se as portas dos cursos nocturnos para os adultos, dêse melhor organisação as escolas normaes, augmentando-se o número d'estas, para que tenhamos bons professores; as actuaes escolasprimárias sejam providas de material escholar e de ensino colloque-se á frente cada uma d'ellas professores distintos pelas suas habilitações, que affianço muito melhoraremos e assim iremos preparando o terreno para estabelecer-se o ensino obrigatorio e outros aperfeiçoamentos que nos ditarem as leis da pedagogia moderna ( $\mathrm{p}$. 11-14).

De certo modo antevê as dificuldades que o Estado encontraria para tornar realidade a obrigatoriedade instituída na Constituição do Estado da Bahia de 2 de julho de 1891 que em seu artigo148, Capítulo I, diz:" O ensino primario será gratuito, obrigatório e universalizado". 


\title{
5 As notícias sobre os aspectos pedagógicos da escola primária na Bahia no início da República
}

Também no primeiro número, o artigo do professor Argemiro Cavalcante intitulado "Considerações sobre o ensino da Leitura e Arithmetica" nos remete às dificuldades para integrar o método intuitivo à prática escolar dos professores da escola primária da Bahia, fazendo uma denúncia:

\begin{abstract}
Quando em todos os países da Europa e América do Norte dá-se instrução as creanças baseando-a no tão preconisado methodo iniciado no século XVII por Comenios, surpehendemos-nos da falta de orientação que tem tido o ensino d'estas disciplinas nas escholas d'este Estado. O regimento interno das Escholas primarias no art. II, f. determina de um modo claro qual a orientação que deve dar o professor ao ensino; porém, causou-nos pasmo vermos a repartição de instrução pública convidar proponentes à fornecimento de livros para uso das escholas primarias, principiando este fornecimento por 5000 cartas de ABC, 5000 taboadas etc[...]. Temos uma lei que determina que o ensino deve ser prático e intuitivo e a adoção destes livros anti-pedagógicos não satisfaz aos requisitos impostos pela lei. Portanto apellamos para o Diretor da Instrução Pública que deve excluir semelhantes libretos da eschola primaria. (CAVALCANTE, 1892).
\end{abstract}

O professor recorre a H.Spencer e Buisson para demonstrar que o ensino da Leitura e da Aritmética "como de todas as mais deve ser do simples para o composto, do indefinido, para o definido, do concreto para o abstrato [...]. A prática tem demonstrado que a criança não comprehende senão o concreto e o synthetico; o que falla aos seus sentidos e o que a interessa; e estes livros são absolutamente contrários á marcha natural da intelligencia infantil" (CAVALCANTE, 1892, p.6 e7).

Em artigos publicados em outros números da revista, o professor dá continuidade a crítica dos livros adquiridos com autorização do Conselho de Instrução Pública e sugere a compra de livros mais adequados à clientela da escola primária e de materiais como o Contador de Chaumil, Pineaux ou um numerador de Chabenat, Ritt, etc. mais condizentes com os princípios do método intuitivo.

A temática do ensino da Aritmética é retomada nos número 8, 9 e 10 pelo professor Pedro Celestino que discorre sobre materiais didáticos inovadores citando autores e pedagogistas que opinaram sobre a utilidade ou inadequação de determinados materiais, ao tempo em que declara a sua posição em relação ao assunto.

No número 8, o professor Theotimo de Almeida ao tratar das questões relativas ao novo horário de funcionamento estabelecido pelo Regimento Interno das escolas primárias, em março de 1891, nos revela importantes aspectos das práticas escolares em uso no início da República. Diante da raridade de descrições que nos possibilitem desvelar o que realmente acontecia nas escolas naquele momento da nossa história, vale transcrever parte do relativamente longo relato e argumentação:

Pelo actual programma e pelo actual horário temos 5 hs e $40 \mathrm{~m}$. de trabalho diário para serem equitativamente divididas por 13 lições que são dadas também diariamente. Dividindo-se o número de horas pelo o de lições a ensinar, temos 26 minutos e 2/18 do minuto para cada trabalho escolar; mas como a escola é de um só grão, dividida em 3 cursos e regida por um só 
professor, dividiremos os ainda os 26 minutos e $2 / 18$ do minuto por 3 [...]Perguntamos: 8 minutos e uma diminutissima fracção do minuto será tempo bastante para um professor fazer convenientemente uma lição prática como devem ser todas as lições escolares que produzam effeitos benéficos, reaes à mentalidade infantil? Certamente que não.

Entremos na evidência prática da nossa argumentação. No ensino da escrita por exemplo, no qual o professor além da fiscalização geral que faz para advertir a creança desviando a da posição anti-hygiênica e anti-pedagógica que por habito commumente tomam os meninos quando escrevem,- tem elle o professor de corrigir as mesmas escriptas individualmente a todos observando os defeitos que comemeteram.

Ora, em uma escola cuja frequencia diaria seja de 40 alunos pelo menos, verse-há o professor obrigado a ir além do tempo que deve neste trabalho dispor, prejudicando assim todas as outras disciplinas da respectiva sessão. O mesmo acontece com o ensino da arithmetica, desenho, etc. Nos perguntarão e o que fazem os monitores que não ajudam o professor? A isso responderemos por mais habilitados e intelligentes que elles sejam, todavia fallecem-lhes conhecimentos quer pratico quer theoricos para transmittirem com precisão irreprochable o ensino á seus collegas; [...], porque também são alumnos, em que ocasião dão elles as suas lições?

Abrindo-se a escola ás 8 horas da manhan como manda a lei, porque na realidade a essa hora não há meninos na escola, e fechando-se ao meio dia, reabrindo-se ás 2 horas da tarde, terminando ás 4 horas é preciso um curso madrugador ou um nocturno para preparar esses sub-professores. Só desta fórma, porque durante o tempo em que regem os cursos não, porque assim ficarão estes prejudicados em virtude de não ter quem os dirigissem enquanto o professor se occupava exclusivamente com os monitores (ALMEIDA, 1893, p.150-151).

O relato informa sobre as dificuldades de por em prática uma norma que interfere na distribuição do tempo dedicado a aprendizagem e no ritmo dos trabalhos escolares. Sinaliza também para a permanência do sistema de monitoria e das classes compostas por alunos em diferentes níveis do ciclo de escolarização. Evidencia, portanto, as dificuldades que a Bahia teve para implantar a escola graduada, apesar de que os currículos prescritos em todo o decorrer da primeira República já incluíam um certo tipo de divisão dos conteúdos da escola primaria conforme os graus ou níveis de escolarização estabelecidos na estrutura legal do ensino. $\mathrm{O}$ autor prossegue apontando (p.151)as diversas alternativas possíveis em relação à forma do professor conduzir o ensino dos conteúdos:

“ Como tornar pois o programma de accordo com o horário e o horário de accordo com o programa"? Ou o professor suicida-se e inutiliza lentamente os seus alunos com o acréscimo de tempo e de trabalho, ou dá as lições de accordo com a lei e neste segundo caso o tempo de que pode dispor não é sufficiente como já provamos, ou corta o programa como se faz ensinando algumas matérias com prejuízos de outras, o que não é admissível porque todas são precisas (Grifo nosso)

Fica evidente um aspecto do currículo em uso na escola que tem origem na incoerência entre norma oficial e realidade da escola e, também, a necessidade de ir além do estudo da legislação para encontrar os documentos que expressam as tensões e conflitos vividos pelos sujeitos reais, que fazem a escola, e para conhecer as saídas por eles encontradas para realizar o seu trabalho. 
Finalizando o autor conclui: "A inexequibilidade do programma e do horário nasce do accumulo dos três gráos em uma só escola dirigida por um só professor". Situação que perdurou ainda por muitos anos.

Como Almeida, diretamente ou nas entrelinhas, os demais autores da Revista do Ensino Primario dão indícios dos aspectos pedagógicos do funcionamento da escola primária na Bahia durante a primeira República e das dificuldades encontradas para implantar a escola graduada e o concretizar outros princípios e normas que permeavam o ideário republicano.

\section{Conclusão}

Os escritos de professores presentes na Revista do Ensino Primária provocam inquietações e dão margem ao levantamento de uma série de questões. Algumas podem ser expressas de imediato e outras dependem ainda de um posterior aprofundamento da reflexão em torno dos conteúdos dos artigos encontrados.

Quanto ao conhecimento revelado pelos professores em seus escritos, pergunta-se: os autores citados presidiram a formação desses professores? Como os professores entraram em contato com eles? Na escola normal? No decorrer de sua vida profissional?

Como se explica a retomada na Revista do Ensino Primário, 12 anos depois, do lema da Revista "A Escola"? Que ligação existiu entre as duas iniciativas? Qual a trajetória profissional e de vida dos professores autores dos diversos artigos? Que outros escritos deixaram esses professores? E, finalmente: Como conhecer ou reconstituir a influência que tiveram na construção da escola primária na Bahia?

$\mathrm{Na}$ caminhada empreendida nesta pesquisa temos reencontrado vários dos nomes presentes nas páginas da Revista do Ensino Primário vinculados a outros eventos e atividades no campo da educação. Encontramos outros escritos, referências a cargos que foram assumindo ao longo da atividade docente e indicação da participação em eventos educacionais. É necessário reconstituir a teia que liga esses nomes entre si e com a escola primária de modo a escrever a história não somente a partir das leis e da biografia das grandes figuras. É preciso conhecer como agiam e como pensavam os atores reais que estiveram dentro das nossas escolas, criando-as e reinventando-as a cada dia. 


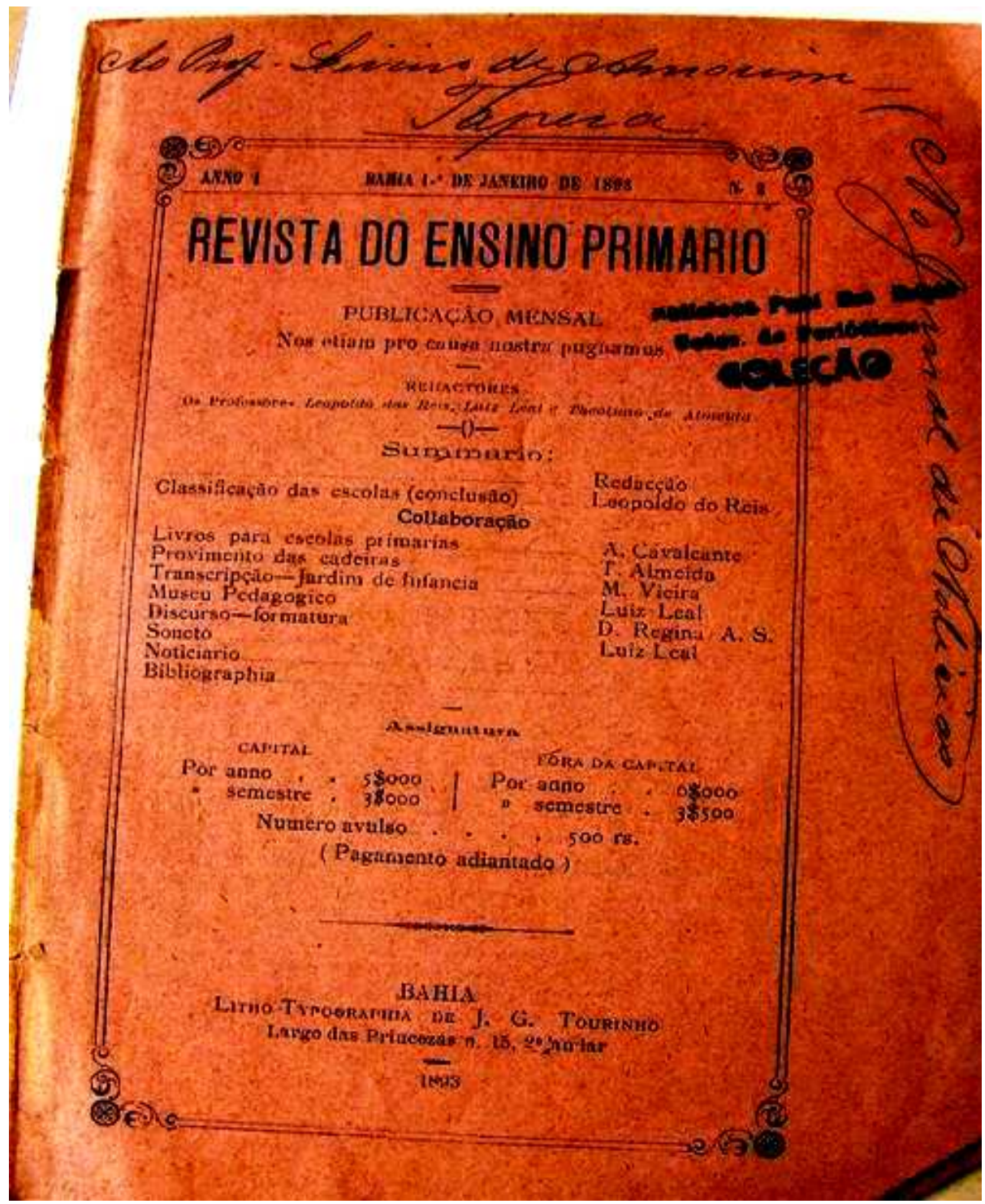

FIGURA 2- Capa do Número 2 da Revista do Ensino Primario Fonte: Biblioteca Pública do Estado da Bahia - Setor de Periódicos Raros

Revista do Ensino Primario: Conteúdo por número publicado entre novembro de 1892 e outubro de 1893 (1) N.1- $1^{\circ}$ DE NOVEMBRO DE 1892

Artigo da redação - L DOS REIS E LUÍS LEAL, p. 1-5. 
Considerações sobre o ensino de Leitura e Arithmetica - A. CAVALCANTE, p. 5-9.

Inspecção das escholas - T. ALMEIDA, p. 9-11.

Obrigatoriedade do Ensino Primário - D. VALLASQUES, p. 11-14.

NOTICIARIO, p. 14-16.

Ao público - A redação, p.17.

Classificação das cadeiras - LEOPOLDO DOS REIS, p. 17-21.

Considerações sobre o ensino de Leitura e Arithmetica(continuação)- A. CAVALCANTE, p. 21-23.

Livro para Eschola Primaria.- A. CAVALCANTE, p. 23-25.

Inspecção das escholas II( Conclusão) - THEOTIMO DE ALMEIDA, p. 26-28.

Escholas normaes e programma de ensino - DIOGO VALLASQUES, p. 28-32.

Organisação do Jardim da Infância ( Transcripção) - p.32-36.

NOTICIARIO, p.16.

N. 3- $1^{\circ}$ DE JANEIRO DE 1892

Classificação das cadeiras (Conclusão)- LEOPOLDO DOS REIS, p.37-39.

Livros para as escolas primárias- ARGEMIRO CAVALCANTE, p.40-43.

Provimento das cadeiras - THEOTIMO DE ALMEIDA, 44-46.

Organisação do Jardim da Infância(Transcripção), 46-48.

Museu Pedagógico. BIBLIOTHECA ESCOLAR - L.LEAL, p.48-49.

Discurso proferido no ato solemne da formatura das alumnas mestras perante a congregação da

Eschola Normal de Senhoras, pela oradora eleita por suas colegas - REGINA DE ALMEIDA

SOARES, p. 50-53.

Jardim da Infancia (A D. Julia Rebello) - LUÍS LEAL, p 53-54.

NOTICIÁRIO, p. 54-56.

BIBLIOGRAPHIA, p. 56.

\section{N.4-1 ${ }^{\circ}$ DE FEVEREIRO DE 1893}

Secções Escolares- LEOPOLDO REIS, p. 57-65.

Livros para as Escola Primarias.- ARGEMIRO CAVALCANTE, p.65-69.

Escolas normaes e programma de ensino - DIOGO VALLASQUES, p. 69-73.

Organisação do Jardim da Infância(Transcripção) - M. VIEIRA, p.73-74.

NOTICIÁRIO - p. 75-76.

BIBLIOGRAPHIA- p.76.

Carta - Mosenhor Solon Pedreira, p.77-79.

N.5-1 ${ }^{\circ}$ DE MARÇO DE 1893

O ensino municipal (redação) - LEOPOLDO DOS REIS, p. 79-85.

Utensílios escolares - L. LEAL, p. 85-86.

O que deve ser a escola (extrahido) - GOMES LEAL, p. 86-89.

Organisação do jardim da infância( TRANCRIPÇÃO - Conclusão), p. 90-95.

NOTICIARIO, p. 95-96.

N.6 $-1^{\circ}$ DE ABRIL DE1893

Ainda o ensino municipal - LEOPOLDO REIS, p. 97-103.

Escolas Primarias - ARGEMIRO CAVALCANTE, p.103-106.

Fiscalização do Ensino - DIOGO VALLASQUES, p.106-109.

Projecto de Reforma da Instrucção Publica do Estado de S.Paulo, p. 109-115,

NOTICIARIO, 116.

BIBLIOGRAFIA, 116.

Cont.

cont. Revista do Ensino Primário

N.7-1º DE MAIO DE 1893

Revista HISTEDBR On-line, Campinas, n.36, p. 70-82, dez.2009 - ISSN: 1676-2584 
Casa Escolar - LEOPOLDO REIS, p. 117-121.

Questões da língua vernácula I - XAVIER MARQUES, p.121-124.

A instrução é necessaria- PEDRO CELESTINO DA SILVA, p. 124-126.

Reforma - LUIS LEAL, p.126-127.

Projecto de Reforma da Instrucção Publica do Estado de S.Paulo(continuação), p. 128-134.

NOTICIARIO, p 134-136.

N.8 - $1^{\circ}$ DE JUNHO DE 1893

Ainda Casa Escolar - LEOPOLDO DOS REIS, p. 137-144.

Questões da língua vernácula - XAVIER MARQUES, p. 145-149.

Inexequibilidade do programma e do horário das escolas primarias - THEOTIMO DE ALMEIDA, p.

149-152.

Fundo escolar - DIOGO VALLASQUES, p.152-153.

O ensino de Arithmetica I - PEDRO CELESTINO, p. 153-155.

Escolas Primarias (continuação) - ARGEMIRO CAVALCANTE, p. 155-156.

N.9 $-1^{\circ}$ DE JULHO DE 1893

Documento importante - LEOPOLDO DOS REIS, p. 157-158.

Memória sobre as Escollas Públicas desta Capitania 1802(extraído de Doc. do Arquivo Público), p.

$158-162$.

A nossa educação - DIOGO VELLASQUES, p. 162- 164.

O ensino de Arithmética II- PEDRO CELESTINO, p.164-166.

TRANSCRIPÇÃO - Pedagogia: OS ELEMENTOS TRADICIONAIS DA EDUCAÇÃO - $1^{\text {a }}$ Parte, $p$.

166- 171.

NOTICIARIO, p.172-176.

BIBLIOGRAPHIA, p. 176.

N.10 - $1^{\circ}$ DE AGOSTO DE 1893

Memória sobre as Escollas Públicas desta Capitania 1802 (Conclusão).

Reforma - Virgílio de Lemos - A REDAÇÃO, p. 81-182.

Ensino Technico - Cicinato Franca, p. 182-185.

O Ensino de Arithmetica III- P. CELESTINO, 185-186.

Representação - Rosa Chaves Ferreira Campos et al. , p. 186-189.

TRANSCRIPÇÃO - Pedagogia: OS ELEMENTOS TRADICIONAIS DA EDUCAÇÃO - $1^{\text {a }}$ Parte

(continuação), p. 189-194.

Nota (sem título) - A REDAÇÃO, p. 194.

NOTICIARIO, p.195- 196.

$$
\text { N.11 - } 1^{\circ} \text {. DE SETEMBRO DE } 1893
$$

O projecto de organisação do ensino - A REDAÇÃO, 197-199.

Projecto de organisação do ensino publico (APRESENTADO PELA COMMISSÃO MIXTA DA

CAMARA DOS DEPUTADOS E SENADO), p. 200-211.

O Ensino de Arithmetica III- P. CELESTINO, p. 211-213.

NOTICIARIO, p. 214-216.

O projecto de organisação do ensino - A REDAÇÃO, 217-218.

O Ensino de Arithmetica IV- PEDRO CELESTINO DA SILVA, p. 218-220.

Projecto de organisação do ensino publico (APRESENTADO PELA COMMISSÃO MIXTA DA

CAMARA DOS DEPUTADOS E SENADO), p. 221-231.

Hygiene Pedagógica - (Extr.), p. 231-234.

NOTICIARIO, p. 234-236.

FONTE: Revista do Ensino Primário. Números de 1 a 12, publicados entre Novembro de 1892 e Setembro de 1893. Setor de Periódicos Raros da Biblioteca Pública do Estado da Bahia.

1. Na indicação do nome dos artigos e dos autores foram preservadas a grafia e forma utilizadas na revista. 


\section{REFERÊNCIAS}

ALMEIDA, Theotimo de. Inexequibilidade do programma e do horário das escolas primarias -

Revista do Ensino Primário. Salvador. N. 8, p. 149-152, Jun. 1893.

ASSIS, Alberto de. Instrução Primaria na Bahia. Diário Oficial. Edição Especial de Centenário. 1923, p.301-315.

BAHIA. CONSTITUIÇÃO DO ESTADO DA BAHIA. Constituição e Leis do Estado da Bahia promulgadas em 1891 e 1892 sob ns. de 1 a 10. Typ e encardenação do " Diário da Bahia". 1892, p.3-44.

BRITTO, Ezequiel (redator chefe). A escola. A ESCOLA. Salvador. N.1, p.1-2, $1^{\circ}$ Set. 1880,

CAVALCANTE, Argemiro. Considerações sobre o ensino de Leitura e Arithmetica Revista do Ensino Primário. Salvador. N.1, p. 5-9, $1^{\circ}$ Nov., 1892.

REIS, Leopoldo. Nos etiam pro causa nóstra pugnamus. Revista do Ensino Primário Salvador.N.1, p. $1-3,1^{\circ}$ Nov. 1892

REIS, Leopoldo; LEAL, Luis; ALMEIDA Theotimo(redatores). Ao Público. Revista do Ensino

Primário. Salvador. N 2, p.17, $1^{\circ}$ Dez. 1892

VALLASQUES, D. Obrigatoriedade do Ensino Primário -.Revista do Ensino Primário. Salvador. N.1, p.11-14, $1^{\circ}$ Nov. 1892.

\footnotetext{
${ }^{1}$ Doutora em Educação, Professora Adjunta do Departamento de Educação I - UNEB, Coordenadora do Projeto "MUDANÇAS CURRICULARES NA CONSTRUÇÃO DA ESCOLA PRIMÁRIA NA BAHIA: Os currículos prescritos nas reformas do ensino e suas relações com o currículo em uso nas escolas (1889-1925)" que tem parte de suas atividades financiadas pela FAPESB e é executado pelo GPEC, Grupo de Pesquisa em Educação e Currículo associado ao Projeto Memória da Educação na Bahia.

${ }^{2}$ Os doze números foram fotografados. As imagens foram impressas e encontram-se agora em fase de aperfeiçoamento para depósito de uma cópia impressa e de um arquivo digitalizado no acervo do Projeto Memória da Educação na Bahia, localizado em uma sala do Programa de Pós-graduação em Educação do Departamento I da UNEB.
}

Artigo recebido em: 10/02/10

Aprovado para publicação em: 16/04/10 